\title{
Interactive comment on "Variability of the Surface Energy Balance in Permafrost Underlain Boreal Forest” by Simone Maria Stuenzi et al.
}

\section{Anonymous Referee \#1}

Received and published: 28 July 2020

Stuenzi et al. use measurements and modelling of surface energy balance processes for a boreal forest and grassland site in Siberia to explore the impact of vegetation characteristics on ground thermal dynamics and snow cover. They couple a 1-D land surface model to a multilayer canopy model to account for radiative transfer through the canopy and for soil thaw dynamics. They find that the forest canopy efficiently reduces solar radiation at the forest floor causing slower soil warming and thaw and delayed snow melt.

The manuscript aims to better describe how vegetation interacts with soil thermal regimes in the continuous permafrost zone of Siberia. The authors provide an important and detailed description of the most relevant vegetation-ground interactions, which can help to better understand permafrost responses in a warming climate. One 
concern is that no radiation, snow, or Bowen ratio measurements were available at the forest site. I know of the difficulties of setting up long-term observations in such environments, but the performance of the model simulations for the forest site - which is the major focus of this paper - cannot be properly assessed without these observations. The authors discuss this shortcoming in the discussion, but - in my opinion - they need to justify better then why the modelling results should be trusted. The modelled forest GST seem to reasonably fit the measured GST, but modelled soil thaw is delayed compared to observations. This raises the question if the modelling results regarding snow phenology are meaningful.

The manuscript provides a good overview and description of the relevant surface energy balance processes, but the authors could highlight how their study advances our understanding of surface energy balance processes in the forested permafrost zone. Bonan and Shugart (1989) outlined many of the relevant interactions and, for example, Chasmer et al. (2011, DOI: 10.1002/ppp.724) present results on forest canopy effects on radiative processes in a permafrost environment.

\section{Other comments}

Page 2, Line 19: In some cases, permafrost thaw and forest loss can also lead to increased $\mathrm{CO} 2$ uptake as shown for thawing ice-rich permafrost in northwestern Canada and Alaska.

Page 3, Line 25: By how much has the summer precipitation decreased?

Page 5, Line 20: How was tree height estimated? Are there any ground-based LAI measurements in similar forest types?

Table 1: Perhaps, the equations in Table 1 could be shown in the table itself or at least qualitatively described. As it is now, the content of the table is not easy to grasp.

Page 6, Line 4: Why did the authors choose the PFT "deciduous needleleaf forest"? They mention that the site is dominated by Picea obovata (92\%). Wouldn't an ever-

Printer-friendly version

Discussion paper 
green needleleaf parameterisation be more adequate? Also, if using the PFT "deciduous needleleaf forest", wouldn't it be necessary to include a phenology module? This is partly discussed later in the manuscript, but should be already mentioned here.

Page 8, line 8: How was soil thermal conductivity parameterised?

Figure 3: What are the error bars showing? What is the input to calculate error bars (hourly, daily, weekly data)? It seems as if the variability (i.e. error bars) for the observed grassland turbulent energy fluxes is much larger than the modelled variability.

Table 2: Is this the same data as shown in Figure 5? If so, the authors could think about showing only one of them (figure or table).

Figure 6: Most of the model-observation comparison is of qualitative nature. The authors could add some performance metrics (e.g., RMSE, R2, bias...)

Page 18, line 12: The authors report a bias in modelled GST during the winter. Since GST measurements are available, the forest-grassland comparison could be more meaningful if it were based on observational data.

Page 22, line 17: Could lateral flow of water contribute to differences in ground water content?

Interactive comment on Biogeosciences Discuss., https://doi.org/10.5194/bg-2020-201, 2020. 